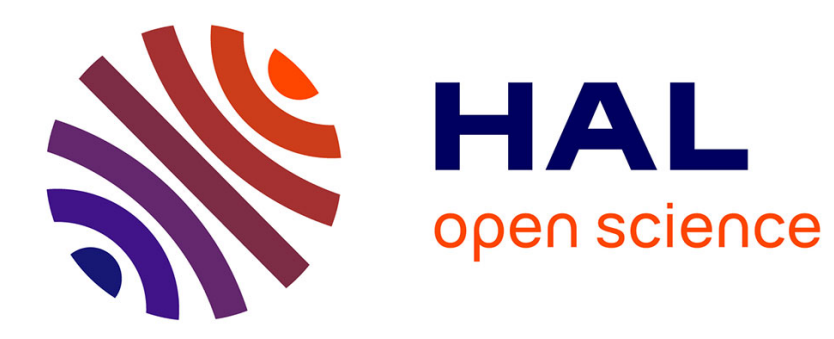

\title{
Innovation from Academia-Industry Symbiosis
}

\author{
Paula Urze, António Abreu
}

\section{To cite this version:}

Paula Urze, António Abreu. Innovation from Academia-Industry Symbiosis. 16th Working Conference on Virtual Enterprises (PROVE), Oct 2015, Albi, France. pp.337-344, 10.1007/978-3-319-241418_30. hal-01437902

\section{HAL Id: hal-01437902 \\ https://hal.inria.fr/hal-01437902}

Submitted on 17 Jan 2017

HAL is a multi-disciplinary open access archive for the deposit and dissemination of scientific research documents, whether they are published or not. The documents may come from teaching and research institutions in France or abroad, or from public or private research centers.

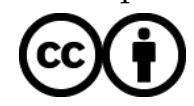

Distributed under a Creative Commons Attribution/ 4.0 International License
L'archive ouverte pluridisciplinaire HAL, est destinée au dépôt et à la diffusion de documents scientifiques de niveau recherche, publiés ou non, émanant des établissements d'enseignement et de recherche français ou étrangers, des laboratoires publics ou privés. 


\title{
Innovation from Academia-Industry Symbiosis
}

\author{
Paula Urze ${ }^{1}$, António Abreu ${ }^{2}$ \\ ${ }^{1}$ FCT/UNL, Faculdade de Ciências e Tecnologia da Universidade Nova de Lisboa, Portugal \\ ${ }^{1}$ CIUHTC - Centro Interuniversitário de História das Ciências e da Tecnologia \\ ${ }^{2}$ ISEL/IPL -Instituto Superior de Engenharia de Lisboa do Instituto Politécnico de Lisboa, \\ Portugal \\ ${ }^{2} \mathrm{CTS}$ - Uninova - Instituto de Desenvolvimento de Novas Tecnologias \\ pcu@fct.unl.pt, ajfa@dem.isel.ipl.pt
}

\begin{abstract}
Anchored on a systemic perspective of innovation and particularly on the triple helix model, which highlights the state, university and companies as central players, this paper aims to discuss the factors that enable or constrain the processes of innovation, using the system thinking approach to understand the academia-industry symbiosis. The paper's empirical section is based on a case study on Portugal's major highway management concessionaire. In order to ensure a "healthy" co-innovation environment, the archetype studied emphasizes the need to implement coordination mechanisms such as communication routines and metrics to monitor collaborative behavior in addition to the need to develop global goals that align the efforts of the partners.
\end{abstract}

Keywords: System Thinking, Triple Helix, Collaborative Networks, Innovation and Case Study.

\section{Introduction}

Today, companies in global markets need to achieve high performance levels and competitiveness just to stay "alive". Recent studies point out that a growing number of innovations introduced in the market come from networks that are created based on the core competences of each member.

In a collaborative environment, the existence of cooperation agreements, norms, reciprocal relationships, mutual trust and common infrastructures allows members to operate more effectively in pursuit of their goals. Partners "split the innovation value chain" into various tasks where the assignment of these tasks to each partner is based on the identification of resources that hold lower costs, and better skills and/or access to specific knowledge, in order to make the outcome more competitive [1].

Furthermore, the synergies created by "confrontation" of different perspectives and sharing experiences in a "healthy" collaborative environment, lead to the reinforcement of innovation flows [2]. The aim in such an innovation environment is to establish mutually beneficial relationships through which new products and services are created, often in close interaction with the customers. 
It is frequently mentioned by many industrial managers that a poor understanding of the drivers that underpin the innovation processes in a collaborative environment is an obstacle for a wider acceptance of this paradigm.

Based on an academia-industry perspective, this paper helps identify and discusses the relevant drivers and barriers that support "healthy" innovation in a collaborative context.

\section{Drivers and Barriers in Industry-Academia Collaboration}

Although collaborative networks have this great potential to both create value and boost innovation, several empirical studies show that many of today's joint ventures fail. According to Lee [3] several types of co-innovation networks can be identified taking into account the diversity of entities that make up the collaborative network such as large companies, SMEs, Universities and research centers, where the roles of each player and the strength of the links differ. Looking at the academia-companies link, there are many types of links that depend on the respective goals and the institutional arrangements. Collaboration to support co-innovation activities can be more or less intense, and also may be formal or informal.

Table 1. Innovations Drivers.

\begin{tabular}{|c|c|c|}
\hline & Drivers of co-innovation & References \\
\hline 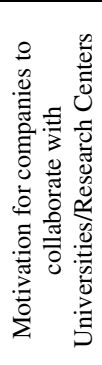 & $\begin{array}{l}\text { Saving costs - access to equipment and physical facilities } \\
\text { Risk Reduction - Access to highly qualified personnel } \\
\text { Reduction of innovation time - access to new technologies and } \\
\text { processes. } \\
\text { Ability to recruit qualified researchers } \\
\text { Develop an innovation culture } \\
\text { Increase the qualification level of employees } \\
\text { Improve public image in society } \\
\text { Access to funding from R\&D funding programs } \\
\text { Source of information for new ideas } \\
\text { Increase product quality } \\
\text { New business opportunities }\end{array}$ & {$[5],[6],[7]$} \\
\hline 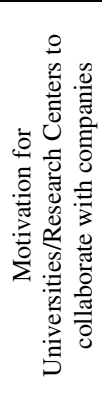 & $\begin{array}{l}\text { Access to industry funding } \\
\text { Access to industrial data } \\
\text { Access to technical knowledge with special impact on research and } \\
\text { teaching activities } \\
\text { Enhancing an entrepreneurial culture } \\
\text { Facilitate graduates' integration into the job market } \\
\text { Postgraduate training in an industrial context } \\
\text { Access to updated technical knowledge } \\
\text { Join networks of knowledge creation and utilization } \\
\text { Reward systems based on amount of technology transfer } \\
\text { Support the creation of spin-offs } \\
\text { Feeling of accomplishment when working with industry/ Good } \\
\text { publicity for the university }\end{array}$ & {$[6],[7],[8]$} \\
\hline
\end{tabular}

In terms of time one can find short-term and long-term collaboration agreements. Short-term collaborations generally consist of on-demand problem solving with 
predefined outcomes. Long-term collaborations are associated with joint projects, often allowing companies to contract a core set of services and to periodically recontract for specific deliverables in a flexible way. Long-term collaborations are more strategic, providing a multifaceted platform where companies can develop a stronger innovative capacity in the long run [4].

The purpose of this section is to address the key factors identified in the literature that are involved in Academia-Industry collaboration. Table 1, shows these factors.

Despite the potential gains obtained from the collaboration between academiaindustry several barriers have been identified in the literature which helps to discuss ways of overcoming these constraints to the innovation processes (see Table 2).

Table 2. Innovations Barriers.

\begin{tabular}{|c|c|c|}
\hline & Barriers to co-innovation & References \\
\hline 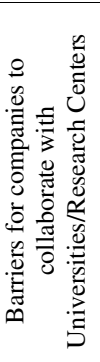 & $\begin{array}{l}\text { Absence of established procedures to collaborate with industry } \\
\text { Lack of information about what universities do } \\
\text { University researchers don't fit in with business culture } \\
\text { Joint projects could imply more risk } \\
\text { Lack of understanding about university expectations } \\
\text { Long-term orientation of university research } \\
\text { Universities seeking to immediate disseminate findings } \\
\text { Knowledge production cycles are shorter and well defined in terms of } \\
\text { technical results } \\
\text { Different perception of the R\&D product (more applied research) } \\
\text { Companies need products and services that can be sold in the market } \\
\text { Companies believe that R\&D needs to remain secret to be competitive }\end{array}$ & {$[9,10,11]$} \\
\hline 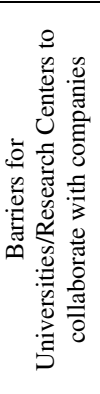 & $\begin{array}{l}\text { Different perception of the R\&D product (more theoretical research) } \\
\text { The nature of the research is not linked to industry's interests and needs } \\
\text { University needs to produce scientific results } \\
\text { University needs to publish results } \\
\text { Knowledge production cycles are longer and less defined in terms of } \\
\text { technical results } \\
\text { Potential conflicts with industry in terms of IPRs } \\
\text { Industry developed knowledge is geared to the market } \\
\text { Industry imposes delays in dissemination of research outcomes and } \\
\text { publications } \\
\text { University is extremely oriented to pure science } \\
\text { Difficulty in finding companies with adequate profile } \\
\text { Short-term orientation of companies' research }\end{array}$ & {$[9,10,11]$} \\
\hline
\end{tabular}

\section{Models to Understand the Innovation Processes}

The National Innovation System theory has attained a dominant position, but over recent decades there have been several new perspectives, which give emphasis to the systemic conception of innovation. Carlsson [12] developed the concept of the technological system in the early 90 s.

Leaving aside the national approach, Carlsson and Stankiewicz [13] defined a technological system as a network of agents interacting in a specific industrial or economic area, within a set of infrastructures involved in the generation, dissemination and use of technologies. The literature on regional systems of 
innovation has grown rapidly since the mid 90s and this time also witnessed the development of the concept of the sectorial system of innovation [14]. Some of the crucial ideas inherent in the innovation system concept (vertical interaction and innovation as an interactive process) emerge in Porter's industrial clusters, as well as in Etzkowitz and Leydesdorff's [15] Triple Helix (TH) theory.

The TH theory highlights the state, university and companies as influential players in the NIS. The TH improves on this (national) innovation model, because it no longer requires the assumption ex ante of national or regional systems for its integration [16]. The TH Model was developed as a result of the convergence and crossing over of the three worlds: research, business and government, which used to be very much separated.

The most recent step in the TH debate has been the concept of the TH system of innovation. This step was introduced and has been integrated into the system as an analytical framework that synthesizes the key features of $\mathrm{TH}$ interactions, defined according to the systems theory as a set of components, relationships and functions [17]. In this new design, among the components of the TH System, a novel distinction has been made between: (1) R\&D and non-R\&D innovators; (2) "single-sphere" and "multi-sphere" (hybrid) institutions; (3) individual and institutional innovators. The new strategic relationships between components have been synthesized into five main types of operations: (1) technology transfer, (2) collaboration and conflict moderation, (3) collaborative leadership, (4) substitution, and (5) networking. This perspective provides an explicit framework for the systemic interaction between $\mathrm{TH}$ actors, which was lacking up to now, and a more fine-grained view of the circulation of knowledge flows and resources within and among the spaces, helping to identify blockages or gaps. Thus, the TH system will generate new combinations of knowledge, resources and relationships which will in turn improve innovation theory and practice. The role of universities in this conceptualization is often mentioned as its "third mission". In fact, the concept of the entrepreneurial university is central to the TH model. As universities forge links, they can combine separate parts of knowledge and bring them together to innovate. Collaborative links with the other innovation actors have improved universities 'production of scientific research over time. Moreover, entrepreneurial universities are now educating organizations as well as individuals and also have an enhanced capacity to generate technology that has shifted their position from a traditional source of human resources and knowledge to a new source of technology generation and transfer. Rather than only serving as a source of new ideas for existing firms, universities are now combining their research and teaching capabilities into new formats and triggering the establishment of new companies, especially in advanced areas of science and technology.

\section{System Thinking to Support the Dynamics of Co-innovation}

According to Hakansson and Snehota [18], to ensure the success of the TH model it is crucial to understand and develop mechanisms to coordinate the complex interactions among university, industry and government, which is impossible to achieve when using linear approaches. 
The tendency to apply models where analysis of the reality is mainly based on a linear approach, where the system behavior and its dynamic is explained through a series of one-way relationship events, together with the predisposition to ignore feedback and delays, might all be obstacles to grasp a better understanding of the dynamics of innovation processes.

Brown and Smith [19] developed a model based on a systems thinking approach to understand the dynamics within networks, as shown in Figure 1. Based on this model the behavior of the network is determined by its causal structure rather than by specific events. This model tries to describe how a successful network might develop and the changes in network behavior and company interaction that might be perceived at each stage. The model consists of several loops that are used to build different stages of the network's development and impact on the performance of both individual firms and all the firms in the network.

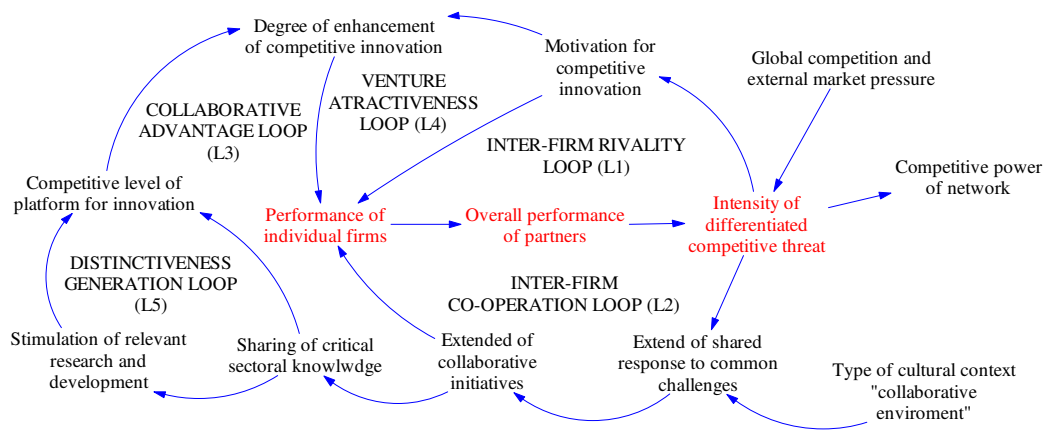

Fig. 1. Cluster Dynamic Model.

An important aspect of the system thinking approach is that certain patterns repeat themselves, allowing an "archetypes" portfolio to be built.

The systems archetypes provide a basic form to describe generic stories and scenarios that can be applied to distinct contexts and environments. Each archetype is built based on a causal loop diagram and offers a common language to understand the behavior and dynamics of a particular system over time. The archetypes can be used to support the decision-making process in two distinct contexts: as a diagnostic tool, it can help managers understand the dynamics of a specific set of behaviors or events that have emerged over time. As a prospective tool, it can help managers identify undesirable behaviors in advance.

The most common systems archetypes are the following: Success to the Successful, Limits to Growth (also known as Limits to Success), Accidental adversaries, Tragedy of the Commons, Growth and Under Investment Attractiveness Principle, Fixes that Fail (also known as Fixes that backfire), Escalation, and Shifting the Burden (also known as Addiction). Considering that at any given time a company is in a state of dynamic equilibrium, the drivers underpinning the innovation processes and the barriers opposing it can be represented using causal loop diagrams. 


\section{Brisa Case Study}

The research was carried out on Portugal's major highway ${ }^{1}$ management concessionaire, and is based on two main projects undertaken by Brisa. The Brisa company currently operates a network of eleven highways, with a total length of around $1096 \mathrm{~km}$, comprising the main Portuguese road links. Given its importance and dimension, Brisa owns several companies specialized in motoring services and geared towards improving the quality of the service provided to customers and increasing its own operating efficiency. The Brisa co-innovation network is a longterm collaborative network.

In order to analyze the sustainability of the link between Universities/Research centers and Brisa in terms of drivers and barriers of co-innovation, as an initial approach an effort was made to find some similarity to the most common systems archetypes mentioned in literature. Taking into account the data collected and the archetypes causal loop diagram, the choice fell on the Accidental adversaries Archetype, whose Causal Loop Diagram is illustrated in Figure 2.

The application of the Accidental adversaries Archetype to this analysis backs up the following explanation: initially, Research Centers/Universities and Brisa begin a relationship with the best of intentions on both sides, with the purpose of maximizing their respective strengths and minimizing their weaknesses. From the perspective of the University/Research Centers, the main goal was to increase their level of prestige. Brisa's goal was to increase the success of its business.

In the first stage, University/ Research Centers establish an alliance with Brisa that benefits both parties. This is a virtuous reinforcing dynamic (R1) - in order to increase their prestige, University/Research Centers carry out R\&D projects and the outcome of the R\&D projects (new technologies and processes) increases Brisa's success. Furthermore, the growth of Brisa's success increases the possibility of recruiting postgraduate students, which creates more prestige for the University/Research Centers. The two reinforcing loops R2 and R3 illustrate the actions taken by University/Research Centers and Brisa to improve their growth, the University's prestige and Brisa's success.

\footnotetext{
${ }^{1}$ These results are based on research carried out in the project - DIINOV - DINÂMICAS DE TRANSFERÊNCIA DE CONHECIMENTO EM REDE DE INOVAÇÃO, FCT/UNL, BRISA, ISEL/IPL, 2015.
} 


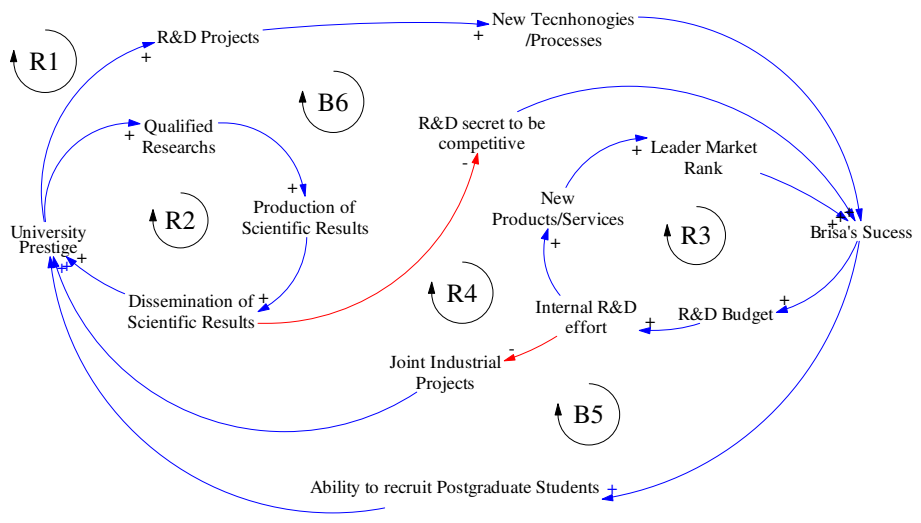

Fig. 2. Influence diagram showing the drivers and barriers of innovation.

However, the problem might arise when one or both parties take some action that looks perfectly reasonable from their perspective. By seeking improvement through R2 and R3, University/Research Centers and Brisa suppress the effects of R1 and establish the negative-effect reinforcing loop R3, which in turn completely takes over B5 and B6. For instance, the dissemination of scientific results based on industrial data may compromise Brisa's competitiveness. The impact of these harmful actions may merely create a sense of frustration and antipathy between the parties, who remain partners, or it may get to the point of turning them into hostile adversaries.

The balancing loop B5 is formed by: Brisa's success, ability to recruit postgraduate students, University prestige, qualified researchers, production of scientific results, R\&D secrecy to be competitive, and Brisa's success.

\section{Conclusions}

This paper discussed the systems thinking approach and the general systems archetypes applied to co-innovation in a collaborative context. The development of models to gain a deep understanding of the dynamics of the co-innovation processes in collaborative environments will not only help to better understand the area, but also contributes to a broader adoption of the collaborative networks' paradigm as a way to develop capabilities that will enable companies to respond quickly to market needs.

In order to ensure a "healthy" co-innovation environment, the archetype studied emphasizes the need to implement coordination mechanisms such as communication routines and metrics to monitor collaborative behavior in addition to the need to develop global goals that align the efforts of all parties involved.

Some preliminary steps in this direction, inspired by system thinking concepts, were presented. Initial results illustrate the applicability of the suggested approach. 


\section{References}

1. Abreu, A., Macedo, P., Camarinha-Matos, L. M. (2008).Towards a Methodology to Measure the Alignment of Value Systems in Collaborative Networks. In: Innovation in manufacturing networks (pp. 37-46).Springer US.

2. Urze; Paula; Abreu, A. (2014). System thinking to understand networked innovation. Collaborative Systems for Smart Networked Environments, IFIP Advances in Information and Communication Technology Volume 434, 2014, pp 327-335.

3. Lee, S., Park, G., Yoon, B., \& Park, J. (2010). Open innovation in SMEs-An intermediated network model. Research policy, 39(2), 290-300.

4. Koschatzky, K., \&Stahlecker, T. (2010). New forms of strategic research collaboration between firms and universities in the German research system.International Journal of Technology Transfer and Commercialisation, 9(1), 94-110.

5. Dooley, L., \& Kirk, D. (2007). University-industry collaboration: Grafting the entrepreneurial paradigm onto academic structures. European Journal of Innovation Management, 10(3), 316-332.

6. Lee, Y. S. (2000). The sustainability of university-industry research collaboration: an empirical assessment. The Journal of Technology Transfer, 25(2), 111-133.

7. Decter, M., Bennett, D., \&Leseure, M. (2007). University to business technology transferUK and USA comparisons. Technovation, 27(3), 145-155.

8. Hall, B.H. (2004). University-industry partnerships in the United States. In Contzen, J.-P., Gibson, D. and Heitor, M.V. (eds), Rethinking Science Systems and Innovation Policies. Proceedings of the 6th International Conference on Technology Policy and Innovation. Ashland, $\mathrm{OH}$ : Purdue University Press.

9. Rohrbeck, R., Arnold, H (2006) Making university-industry collaboration work - a case study on the Deutsche Telekom Laboratories contrasted with findings in literature, ISPIM, Conference, - Networks for Innovation, Greece.

10. Ramil, M, Senin, A. (2014)Success factores to reduce orientation and resources related barriers in university industry R\&D Collaboration particularly during development research stages, Global Conf Bus. \& Social Sc., Procedia Social \& Behav. Sciences, 172, 375-382.

11. Bekkers, R., Freitas I. (2010). Catalysts and barriers: factors that affect that affect the performance of university-industry collaborations, Conference on Innovation, Organisation and Sustainability and crises, Aalborg.

12. Carlsson, B. (1995). Technological Systems and Economic Performance: the Diffusion of Factory Automation in Sweden, Springer Science, Business, Media, New York.

13. Carlsson B. and Stankiewicz R. (1991) On the nature, function and composition of technological systems, Journal of Evolutionary Economics, 1 (2), 93 - 118.

14. Lundvall, B.-Å. and S. Borras (2005), 'Science, Technology, Innovation and Knowledge Policy', in Fagerberg, J., D. Mowery and R.R. Nelson (eds.), The Oxford Handbook of Innovation, Norfolk, Oxford University Press.

15. Leydesdorff, L. and Etzkowitz H. (1998) The Triple Helix as a Model for Innovation Studies, Science \& Public Policy Vol. 25(3) 195-203.

16. Leydesdorff, L. (2005) The Triple Helix Model and the Study of Knowledge-Based Innovation Systems, Int. Journal of Contemporary Sociology 42(1), 12-27.

17. Ranga, M. and Etzkowitz H. (2013) The Triple Helix Systems: An Analytical Framework for Innovation Policy and Practice in the Knowledge Society, Industry and Higher Education, 27 (4): 237-262.

18. Snehota, I., \&Hakansson, H. (Eds.). (1995). Developing relationships in business networks. Routledge.

19. Smith, M., \& Brown, R.(2009). Exploratory techniques for examining cluster dynamics: a systems thinking approach. Local Economy, 24(4), 283-298. 